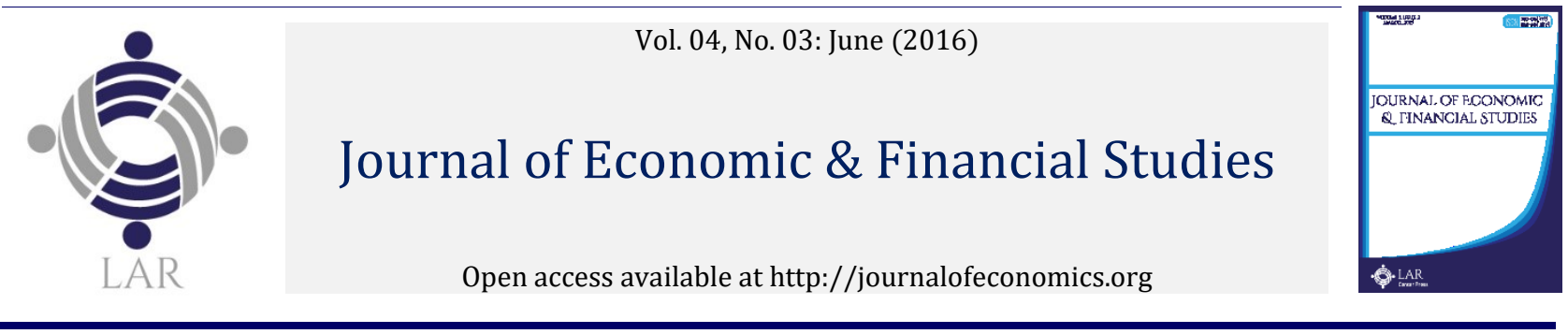

\title{
Older adults and fraud: Suggestions for policy and practice
}

\author{
Olivia DaDalt a* \\ a Research Associate, MIT AgeLab, Massachusetts Institute of Technology, Cambridge, MA 02139-4307 \\ ${ }^{*}$ Corresponding author's email address: odadalt@mit.edu
}

\section{A R T I C LE I N F O}

Received: 29-05-2016

Accepted: 27-06-2016

Available online: 16-07-2016

Keywords:

Aging population;

Economic fraud;

Prosperity.

\begin{abstract}
A B S T R A C T
In this study, I examine the issue of the vulnerability of older adults especially with regard to be a potential victim of economic fraud. A general review of current facts and figures suggest that financial fraud against older adults is rising across U.S.A totaling $\$ 36$ billion. Unfortunately, most of the older adults are the baby boomers' generation, who grow up in a relative peace and prosperity condition while facing much difficult financial realities in their old life. Result also suggest the intensity of facing financial frauds by older adults are correlated with their low level of financial literacy. Given the wider context of this phenomenon, I propose some policy measures to safeguard the financial interest of the older adults.
\end{abstract}

(C) 2016 The Authors. This is an open access article under the terms of the Creative Commons Attribution License 4.0, which allows use, distribution and reproduction in any medium, provided the original work is properly cited.

DOI: http://dx.doi.org/10.18533/jefs.v4i3.229

ISSN 2379-9463(Print), ISSN 2379-9471(Online)

\subsection{The context: Aging as a success story}

The world's population is aging, and the US is no exception. Innovations in technology, medicine and public health have resulted in longer life spans; compared with 60 years ago, Americans enjoy on average an extra decade of life (Arias, 2014). Overall, Americans' life expectancy at birth was 79.1 years in 2010, compared with only 68.2 in 1950. Longer life spans have led to a burgeoning older adult population, in sheer numbers as well as in percentage of the population (see Figure 1). This population growth is changing the demographic makeup of the US. In this regard, we can count aging as a true success story.

Yet the significance of the older adult generation lies not only in its size but also in its economic power. Older Baby Boomers (born 1946-1955) are wealthier than the generations before them, with a median net worth of $\$ 241,333$, a 34\% increase over that of the War Babies generation (born 1936 -1945) and a 39\% increase over that of the Depression Babies (born 1926-1935) (Bloomberg, 2013). Older adults also represent greater purchasing power. Nielsen reported that the 50+ population consists of nearly 100 million consumers who are responsible for $\$ 230$ billion worth of sales in consumer packaged goods, a whopping $49 \%$ of total sales (Nielsen \& Boomagers, 2012). And this trend is not expected to end any time soon: by 2017, half of the US population will be age 50 or older and will control fully $70 \%$ of the country's disposable income (Nielsen \& Boomagers, 2012). A University of Cincinnati study on $50+$ consumers concluded that "the world has never before seen such a powerful market," with $\$ 3$ trillion to spend in the U.S. alone (Boyle, 2013). Nielsen \& Boomagers (2012) echoed this assertion, noting that "Boomers have the most money and spend the most money.... [and] as more Boomers age out of their prime income earning years, they will move from a life dedicated to making money to one that is directed to spending money." As AARP spokeswoman Jody Holtzman commented, "You'd have to be an idiot to turn your back on this humongous market" (Boyle, 2013). 
Figure 1: Population of Older Adults in the US, Ages 65+, 1900-2050.

$100,000,000$

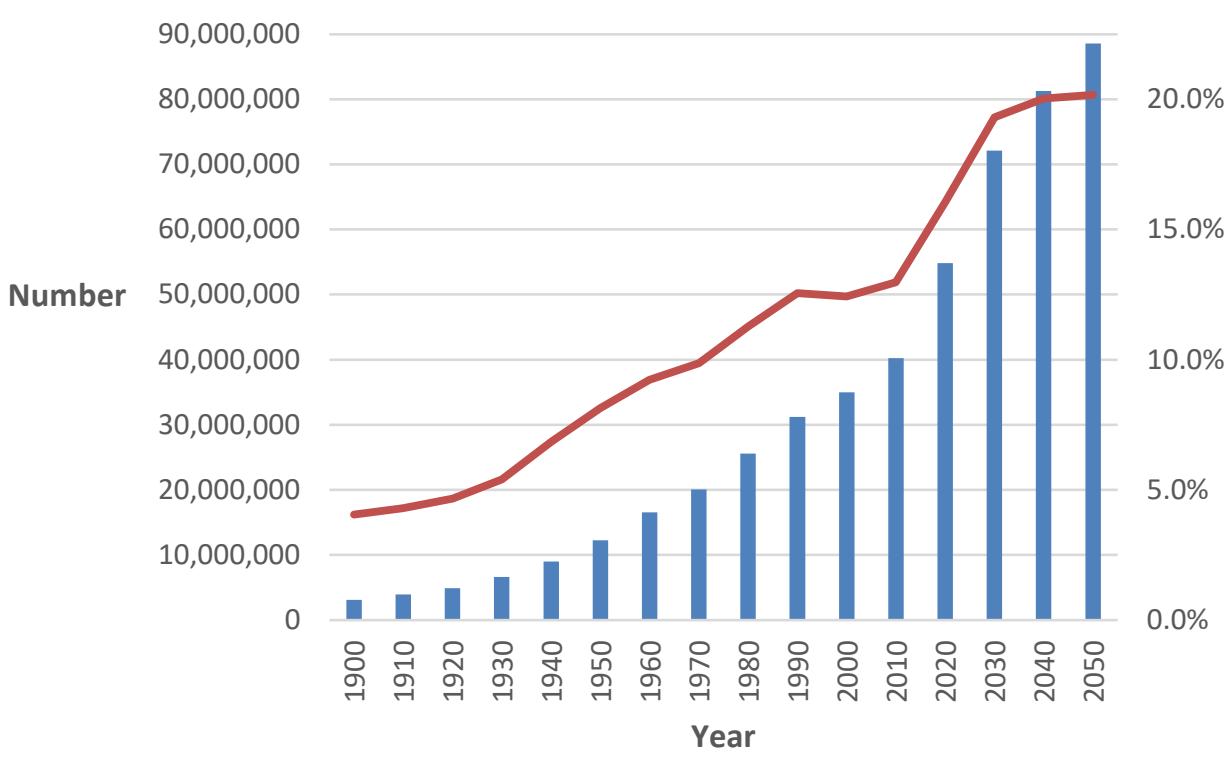

$25.0 \%$

Percent of population

Number of people age $65+$

$\longrightarrow$ Percent of people age $65+$

Data source: Administration for Community Living, Administration on Aging (2015).

\subsection{The problem dynamics}

\section{$2.1 \quad$ Pitfalls of prosperity}

Con artists, scammers, and other perpetrators of financial fraud and abuse are clearly not idiots, however. In 2010 , one fifth of Americans over the age of 65 reported in a telephone survey that they had been subject to some sort of financial fraud or abuse (Investor Protection Trust, 2010). Fraud against older adults is also on the rise, totaling $\$ 2.6$ billion in 2008 and increasing a frightening 12\% to $\$ 2.9$ billion the following year (2009) (MetLife, 2011). This may even be an underestimate of the actual dollar amount, as it is difficult to know the true extent of financial fraud or abuse of older adults; a separate survey study of older adults ages 50 to 70 put the estimated cost of older adult fraud at $\$ 36.48$ billion (True Link, 2015). It is thought that many such instances of financial fraud and abuse are unreported to law authorities, because the individual in question: is ashamed of the abuse that has taken place at the hand of a family member or friend; does not know how or lacks the ability to report the abuse; fears retribution from the abuser; or fails to recognize the fraud as such (National Center for Elder Abuse, 2015). In fact, one study hypothesizes that only as many as 1 in 44 cases of financial abuse are reported (Lachs \& Berman, 2011). And although many Boomers have been successful, it is not only wealthy seniors who have attracted scammers' eyes; most studies show no link between income and prevalence of financial abuse (USDOJ, n.d.). Indeed, if one has nothing to lose, why not take a friendly caller up on an offer to make $\$ 10,000$ ? As Cindy Hounsell of the Women's Institute for a Secure Retirement (WISER) explained "[older women] feel badly they have nothing to leave [their relatives], then someone calls up and says, 'You just won!' They all say the same thing - that's why [these women] fall for it" (Covert, 2014).

According to the 2010 MetLife study, the most commonly reported type of financial fraud or abuse of older adults in media stories was perpetrated by strangers in the form of telephone scams, home repair scams, or simple burglary (51\%) (MetLife, 2011). The second most commonly covered type was by family, friends, neighbors, or caregivers who took advantage of the individual's generosity and/or financial incapacity (34\%), followed by fraud or abuse by businesses or professionals such as insurance companies, banks, contractors, attorneys, or nursing home administrators (12\%). Medicaid or Medicare fraud was least commonly reported in news articles (4\%). According to the FBI and the National Council on Aging (NCOA), scams can involve anything from selling fraudulent anti-aging products, to telemarketers seeking to confuse or coerce older adults into buying items or services they do not need, to scammers pretending to be the person's grandchild or other relative and asking for money to help solve a personal problem (NCOA, n.d.; United States Senate Special Committee on Aging, 2016). Thus, while older adults may rightly be wary of strangers and big companies, family members and caregivers who are well-known to the older adult may also try to take financial advantage of him or her. 
2.2 Trust, vulnerability and the aging brain

So why do older adults seem to be particularly vulnerable to financial abuse and scams? Part of the answer may be that older adults in general seem more trusting than other age groups. When it comes to trust in others, research shows that Boomers are more trusting relative to other generations. When asked "do you feel that most people can be trusted," Boomers gave the highest percentage of "yes" answers, indicating that they have a higher level of trust in other people (Ellis \& Coughlin, 2014).

Figure 2: Trust in others by generation.

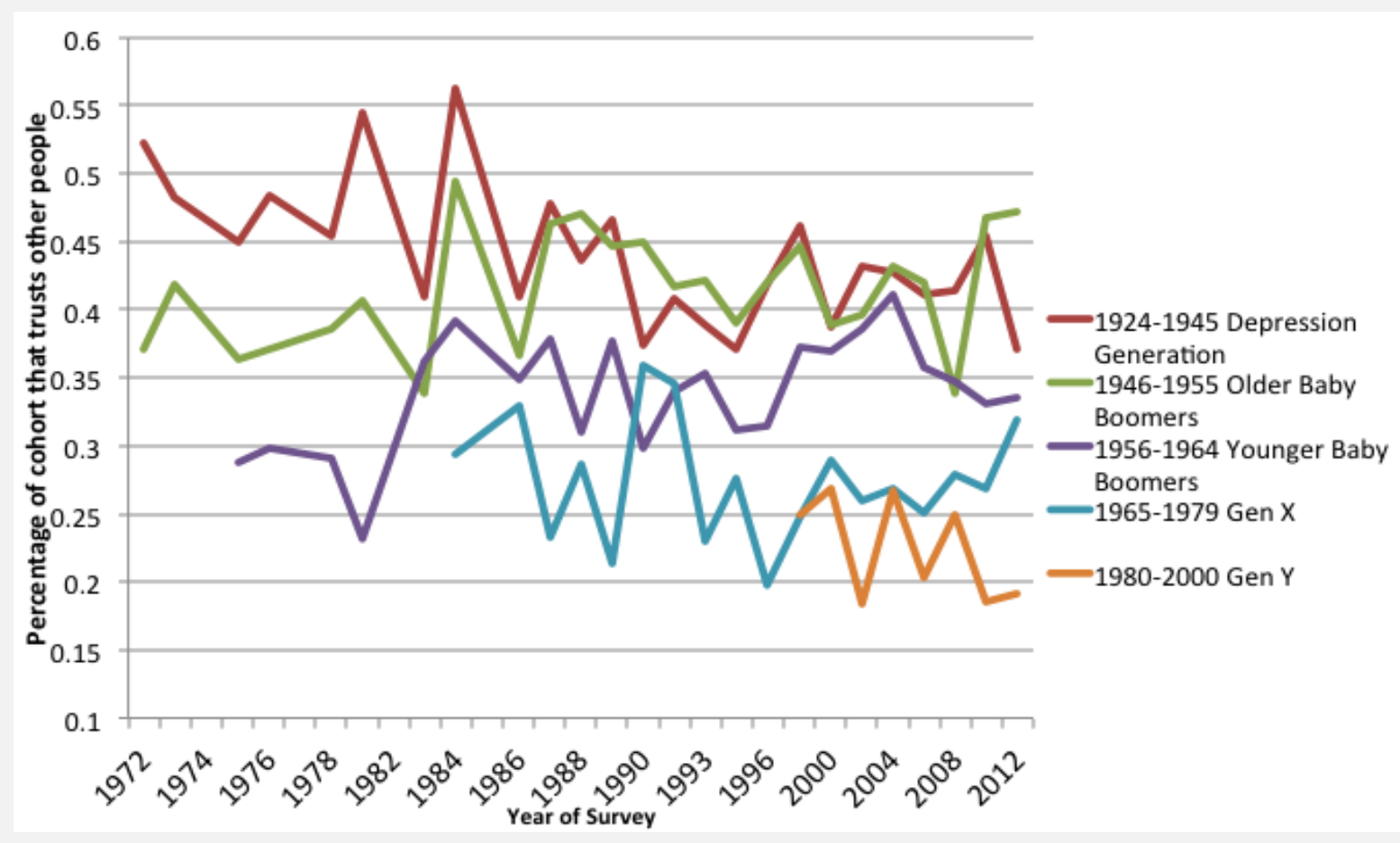

Source: Ellis, D. \& Coughlin, J.F. (2014).

Notes: The lines represent the fraction of each generation that answered yes to the question, "Do you feel that most people can be trusted?" Boomers gave the highest percentage of "yes" answers, indicating that they have a higher level of trust in other people. Data were from the General Social Survey.

These higher levels of trust in others among older adults may have something to do with actual changes in the brain. In a study by Castle et al. (2012), participants were shown faces that had cues as to their trustworthiness or untrustworthiness. They found that older participants perceived the untrustworthy faces as significantly more trustworthy and approachable than younger participants did. Interestingly, when viewing these untrustworthy faces, older participants also showed less activation of the anterior insula, a part of the brain known to support interoceptive awareness, or what is commonly called a "gut feeling." These gut feelings warn of potential risks or dangers, such as an untrustworthy person. Decreased activity in the anterior insula portion of the brain in older adults may suggest that their awareness or assessment of risk is not as strong as that of their younger counterparts, which in turn may contribute to a greater vulnerability to fraud and scams. Castle et al. (2012) state that "on the whole, this pattern of lesser sensitivity to negative cues, such as those that cue untrustworthiness, may be a benign contribution to the well-being of older adults much of the time. However, this propensity may also put older adults at risk for failing to process cues to untrustworthiness that they should attend to" (p. 20851).

The so-called "positivity bias," or tendency to devote more attention and memory to positive information in general and to downplay negative, is another common occurrence among older adults (Carstensen, 1993; Charles et al., 2003). Also related to changes in the brain, this bias seems to exist to help keep older adults' moods and morale high (Brassen, Gamer \& Büchel, 2011). Yet despite these potential benefits, this bias can have perilous consequences for their financial security, leading them to ignore warning signs such as the aggressiveness or insistence of a telemarketer and to focus only on the potential rewards or profits they promise (Harle \& Sanfey, 2013; Samanez-Larkin et al., 2013; Scheibe et al., 2014).

Another possible explanation for older adults' increased vulnerability to fraud may be that financial capacity itself may decline with age. Some research, as shown in Figure 3, has found that older adults are significantly worse at financial decision-making, with one study even suggesting that financial literacy scores decrease by $1 \%$ each year after age 60 (e.g., Gamble et al., 2015; Finke, Howe \& Huston, 2011). 
Figure 3: Financial literacy score by age.

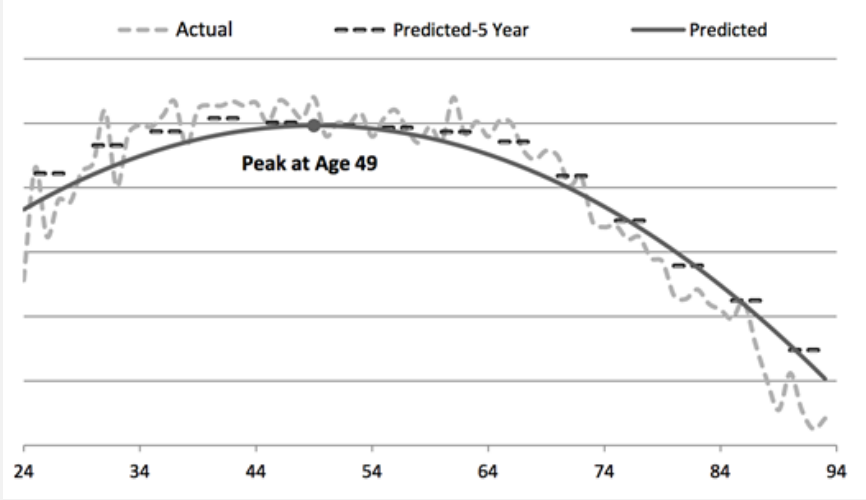

Source: Finke, Howe \& Huston (2011).

Note: "The figure shows mean CFM [Consumer Monthly Finance] financial literacy scores for each year of age and predicted financial literacy scores using regression estimates when age is specified as age and age-squared, and as a 5-year-age groups, in a regression mode that controls for household characteristics" (Finke, Howe \& Huston, 2011, 35).

Finke, Howe \& Huston (2011) found that although financial capacity seemed to decline with age, financial confidence did not: essentially, individuals maintained the belief in their own financial abilities even while they were eroding. This lack of awareness of their changing financial capacities could also put older adults at higher risk for financial fraud or abuse. Further, if they are unaware of their own shortcomings, they might see no reason to be more cautious about money, to monitor themselves, or to question decisions to ensure that they are financially sound. It is easy to see how these factors could combine, resulting in an individual who is both overly trusting of others and overly confident in his or her own declining financial capacity: a perfect target for scams and financial abuse.

\subsection{Solutions and next steps}

\subsection{Policy}

In order to reduce older adults' susceptibility to fraud and scams, wider financial education must be made available to these individuals and their families. This education should help older adults identify common scams, how and when they occur, and how to avoid them. Families should also be educated about common warning signs of financial incapacity in their loved ones, which can itself be a sign of dementia or general cognitive decline (Marson, 2013; Sabatino, 2011; Widera et al., 2011). All of this information should also be distributed in the financial advising industry to make advisors aware of how to help combat fraud for their clients. Many organizations offer tips for avoiding scams, and while many of them seem to be simple common sense, such as "just say no" or "hang up," others may prove more useful, especially for consumers who may become easily confused. A number of sources, for example, suggest setting up direct deposit for benefit checks to avoid the risk of having them stolen through the mail, shredding all documents with credit card or social security numbers, and insisting on receiving written material before agreeing to any service or donating to any cause (Hounsell, 2009; NCOA, n.d.; Kirchheimer, 2013; United States Senate Special Committee on Aging, 2016). For a more complete list of resources with advice to help protect older adults against fraud, see the Appendix.

\subsection{Practical solutions}

Older adults and their families need to make comprehensive financial plans that incorporate decisions about health care, future housing options, asset management, and contingencies to account for any possible financial incapacity, such as power of attorney arrangements, living trusts, or financial advocates. It is important to put these plans in place early, to avoid any uncertainty or confusion that might expose older adults to a greater risk of exploitation or fraud.

Beyond educating older adults, family members and caregivers about the risks of financial fraud and abuse, there are technological weapons available for combatting fraud. A few new options have surfaced in recent years; services such as these may be suitable for some older adults and their families:

- The Jolly Roger Telephone Company: An artificial intelligence system that allows people to patch telemarketers to a voice recording that can respond to the telemarketer. The program is able to sense tone 
and pauses in speech and responds with vague sounds like "mmm" or "sure," or even occasionally claims to be "just woke[n] up from a nap, and still kind of groggy" and asks the caller to repeat what he or she had just said. This confuses the telemarketers and avoids the risk of scammers speaking directly to an older adult themselves, although the older adult would have to be cognizant enough to patch callers through to the system. http://jollyrogertelephone.com/

- True Link Financial: This company offers customizable debit cards that can be modified to work only for certain merchants and companies or only for certain kinds of purchases (e.g., no telephone or on-line purchases), effectively blocking telemarketers and scammers. A family member or user can also manage cash withdrawals and set spending limits, and he or she can see whatever a paid caregiver might spend on behalf of an older adult. https://www.truelinkfinancial.com/

- BillGuard: A mobile phone app that sends credit or debit card charges to the user's email in real time, so they can keep track of any fraudulent or suspect charges. The app can also be used to track the physical location of where credit card charges are made and to alert users to other possibilities of financial fraud, such as if someone tries to sign up for a credit card or loan in their name. A caregiver could set up a parent's card to sync to the caregiver's email account, allowing them to monitor the loved one's credit card discreetly and financial transactions without taking the card away. https://www.billguard.com/

This list is not an endorsement, but merely a few examples of the numerous technology-based services that exist to help protect individuals and families from financial crimes. Financial advisors, older adults, and families should assess services such as these to determine if they are a good fit for their individual situations.

Some of the responsibility for education should also lie with national institutions such as the IRS, the Investor Protection Trust, or the National Center for Elder Abuse. One or multiple of these institutions should endeavor to publish annual, or perhaps quarterly, reports on the latest and most frequently occurring scams being perpetrated across the country and email, call, or mail this information to the general public, to raise awareness of these scams and warn older adults and families to be on their guard. Many currently publish online guides or pamphlets, but such resources aren't doing individuals any good if they don't know how to access them or whether they exist at all. These institutions should make it a priority to get this information into consumers' hands.

In terms of other policy innovations, our government should increase criminal penalties for the perpetrators of fraud and also hold banks and credit-card companies more accountable for any scams committed on their watch.

\subsection{Future research}

More research on older adults and fraud is also needed to identify the best solutions for combatting it. While there is already research suggesting that forewarning of scams results in lower fraud susceptibility among older adults (Scheibe et al., 2014), it would be helpful to know exactly which types of warnings are the most successful (phone calls? email? pamphlets?) and the amount of time for which each warning remains effective, i.e., do consumers forget about the warning after a month or so and become vulnerable to fraud once again? Future research should also examine the connection between the aforementioned positivity effect and fraud in order to determine the extent to which older adults' inclination toward positive information is actually a threat to them.

Yet even as technological, policy, and practical solutions to combat elder fraud continue to grow and improve, so too will the tricks and contrivances of people who would seek to defraud and steal from older adults. Older adults, family members, and financial advisors must work together to keep seniors informed about the risks and about ways to keep their money and financial futures safe.

\section{References}

Arias, E. United States Life Tables, 2010. National Vital Statistics Reports. National Vital Statistics System. Retrieved from http://www.cdc.gov/nchs/data/nvsr/nvsr63/nvsr63_07.pdf.

Boyle, M. (2013). "Aging boomers stump marketers eyeing $\$ 15$ trillion prize." Bloomberg News. Retrieved from http://www.bloomberg.com/news/articles/2013-09-17/aging-boomers-befuddle-marketers-eying-15trillion-prize.

Bloomberg Visual Data. (2013). "Preparing for the mature consumer boom." Retrieved from http://www.bloomberg.com/infographics/2013-09-17/preparing-for-the-mature-consumer-boom.html.

Brassen S., Gamer M., and Büchel C. (2011). Anterior cingulate activation is related to a positivity bias and emotional stability in successful aging. Biol Psychiatry, 70, 131-137. http://dx.doi.org/10.1016/j.biopsych.2010.10.013 
Carstensen, L.L. (1993). "Motivation for social contact across the life span: A theory of socioemotional selectivity." In Nebraska Symposium on Motivation: 1992, Developmental Perspectives on Motivation, Volume 40, 209254, J.E. Jacobs (ed.). Lincoln: University of Nebraska Press.

Castle E., Eisenberger N. I., Seeman T. E., Moons W. G., Boggero I. A., Grinblatt M. S., and Taylor, S.E. (2012). Neural and behavioral bases of age differences in perceptions of trust. Proceedings of the National Academy of Sciences of the United States of America 109(51), 20848-20852. http://dx.doi.org/10.1073/pnas.1218518109

Charles, S. T., Mather, M., \& Carstensen, L. L. (2003). Aging and emotional memory: the forgettable nature of negative images for older adults. Journal of Experimental Psychology: General, 132(2), 310. http://dx.doi.org/10.1037/0096-3445.132.2.310

Covert, B. (2014). How your grandma could lose her home and her savings. Retrieved from http://thinkprogress.org/economy/2014/06/05/3445518/widows-financial-insecurity/.

Ellis, D. and Coughlin, J.F. (2014). Just when we need it most: Trust, technology, and navigating old age. Public Policy and Aging Report, 24(1), 18-20. http://dx.doi.org/10.1093/ppar/prt004

Finke, M.S., Howe, J., and Huston, S.J. (2011). Old age and the decline in financial literacy. Working paper. Retrieved from http://ssrn.com/abstract $=1948627$.

Gamble, K.J., Boyle, P.A., Yu, L., and Bennett, D.A. (2015). How does aging affect financial decision making. Issue Brief 15-1. Center for Retirement Research at Boston College, Chestnut Hill, MA.

Harlé, K.M., \& Sanfey, A.G. (2012). Social economic decision-making across the lifespan: an fMRI investigation. Neuropsychologia, 50(7), 1416-1424. Retrieved from doi.org/10.1016/j.neuropsychologia.2012.02.026

Hounsell, C. (2009). Protecting your mother from financial abuse and fraud. In Elder Abuse: A Women's Issue, 1822. Retrieved from http://www.owl-national.org/Mothers_Day_Reports_files/OWL_MothersDay_Report_ 09_Final_2.pdf

Investor Protection Trust. (2010). Elder investment fraud and financial exploitation: A survey conducted for investor protection trust. Retrieved from http://www.investorprotection.org/downloads/EIFFE_Survey_ Report.pdf.

Kirchheimer, S. (2013). Protect your parents from scams. AARP, Washington, DC. Retrieved from http://www.aarp.org/money/scams-fraud/info-08-2013/protect-your-parents-from-scams.html.

Lachs, M. S., \& Berman, J. (2011). Under the radar: New York State Elder Abuse Prevalence Study. William B. Hoyt Memorial New York State Children, Family Trust Fund, New York State Office of Children and Family Services. Retrieved from http://ocfs.ny.gov/main/reports/Under\%20the $\% 20$ Radar $\% 2005 \% 2012 \% 2011 \% 20$ final\% 20report.pdf

Marson, D.C. (2013). Clinical and ethical aspects of financial capacity in dementia: A commentary. American Journal of Geriatric Psychiatry, 21(4), 382-389. http://dx.doi.org/10.1016/j.jagp.2013.01.033

MetLife Mature Market Institute. (2011). The MetLife study of elder financial abuse: Crimes of occasion, desperation, and predation against America's elders. Retrieved from https://www.metlife.com/mmi/ research/elder-financial-abuse.html.

National Center for Elder Abuse. (2015). Statistics. Retrieved from http://www.ncea.aoa.gov/ Library/Data/index.aspx.

National Council on Aging (NCOA). (n.d.) 22 senior scams you must know and avoid. Retrieved from https://www.ncoa.org/economic-security/money-management/scams-security/22-tips-to-avoid-scamsswindles/.

Nielsen and Boomagers, LLC. (2012). Introducing Boomers - Marketing's most valuable generation. Retrieved from http://www.nielsen.com/content/dam/corporate/us/en/reports-downloads/2012-Reports/nielsenboomers-report-082912.pdf.

Sabatino, C.P. (2011). Damage prevention and control for financial incapacity. Journal of the American Medical Association, 305(7), 707-708. http://dx.doi.org/10.1001/jama.2011.187

Scheibe, S., Notthoff, N., Menkin, J., Ross, L., Shadel, D., Deevy, M., and Carstensen, L.L. (2014). Forewarning reduces fraud susceptibility in vulnerable consumers. Basic and Applied Social Psychology, 36(3), $272-279$. http://dx.doi.org/10.1080/01973533.2014.903844

Samanez-Larkin, G.R., Li, S.C., and Ridderinkhof, K.R. (2013). Complementary approaches to the study of decision making across the adult life span. Frontiers in Neuroscience, 7, 243. http://dx.doi.org/10.3389/ fnins.2013.00243

True Link. (2015). The True Link report on elder financial abuse 2015. Retrieved from https://truelinkwordpress-assets.s3.amazonaws.com/wp-content/uploads/True-Link-Report-On-Elder-Financial-Abuse012815.pdf.

United States Senate Special Committee on Aging. (2016). Fighting fraud: U.S. Senate Aging Committee identifies top 10 scams targeting our nation's seniors. Senate Report, No. 114-208. Retrieved from http://www.aging.senate.gov/imo/media/doc/217925\%20Fraud\%20Book\%20Final.pdf.

United States Department of Justice (n.d.). Elder Justice and Prosecution. Retrieved from https://www.justice.gov/elderjustice/financial/faq.html 
Widera, E., Steenpass, V., Marson, D., and Sudore, R. (2011). Finances in the older patient: He didn't want me to take over. Journal of the American Medical Association, 305(7), 698-706. http://dx.doi.org/10.1001/ jama.2011.164

\section{Appendix}

\section{Resources to Help Protect Older Adults from Financial Fraud and Abuse}

\section{Adult Protective Services (APS)}

First responders who investigate cases of elder abuse; the website provides fact sheets and contact information, as well as a checklist for indicators of possible financial abuse that should be reported. http://www.napsanow.org/get-informed/what-is-financial-exploitation/

\section{AARP Fraud Watch Network}

Lists and descriptions of recent scams to beware of, links to resources and help, and quizzes to determine the user's knowledge of and vulnerability to scammers. Users can also sign up for Watchdog Alerts that provide information about the latest scams and offer prevention tips to avoid them. http://www.aarp.org/money/scamsfraud/fraud-watch-network/?intcmp=AE-MON-CONP-SPOT2-FWN

\section{Financial Industry Regulatory Authority (FINRA)}

A national not-for-profit organization authorized by Congress to regulate the securities industry. Provides fact sheets and brochures with quick, digestible information, such as "How to Spot a Scam in 6 Steps" and "Red Flags of Fraud." Includes a game "Con 'Em If You Can" to help people identify common tactics used to perpetuate fraud. http://www.finra.org/investors/avoid-fraud and http://www.conemifyoucan.org/?utm_campaign=ConEm Game\&\%3Butm_medium=FINRASite\&\%3Butm_source=AvoidFraud

\section{Investor Protection Trust}

A national non-profit organization dedicated to protecting and educating investors. Includes brochures, pamphlets and activities to help adults identify and protect themselves against fraud. Home to the Elder Investment Fraud and Financial Exploitation (EIFFE) Prevention Program. The EIFFE Program trains professionals to recognize if their older adult clients (especially those who may be contending with cognitive decline) may be vulnerable to or victims of financial fraud or abuse and provides information about appropriate referrals for assistance. http://www.investorprotection.org/protect-yourself/?fa=protect-seniors

\section{National Council on Aging (NCOA)}

A dedicated section for financial education with resources to teach older adults improved financial management skills and literacy. Includes the Savvy Seniors Saving Toolkit 2: Steps to Avoiding Scams. This toolkit and other educational materials can be downloaded for free and presented in workshop form. https://www.ncoa.org/economic-security/money-management/

\section{National Crime Prevention Council (NCPC)}

Fliers, palm cards, and public service announcements to encourage older adults to protect themselves against and to report fraud. http://www.ncpc.org/topics/crime-against-seniors

\section{OnGuard Online}

A website by the federal government dedicated to keeping all Internet users safe online. Contains information about different types of scams and how to keep safe online, along with blog posts relating specifically to financial abuse of older adults. Offers videos and games to illustrate the principles of online safety. www.onguardonline.gov

United States Senate Special Committee on Aging's Fighting Fraud: U.S. Senate Aging Committee Identifies Top 10 Scams Targeting Our Nation's Seniors

A report from the US Senate detailing different types of fraud in the US and how to combat them. Provides an extensive list of resources. http://www.aging.senate.gov/imo/media/doc/217925\%20Fraud\%20Book\%20 Final.pdf

\section{Women's Institution for a Secure Retirement (WISER)}

Non-profit dedicated to ensuring the long-term financial security for women, has a number of fact sheets and publications to help people guard against to financial abuse. http://www.wiserwomen.org/index.php?id=53\& page $=$ Fact_Sheets - Scams, Frauds, and Elder Financial Abuse 